\title{
Use of Space-Resolved in-Situ High Energy X-ray Diffraction for the Characterization of the Compositional Dependence of the Austenite-to-Ferrite Transformation Kinetics in Steels
}

\author{
Imed-Eddine Benrabah ${ }^{1}$, Hugo Paul Van Landeghem ${ }^{1}{ }^{\mathbb{D}}$, Frédéric Bonnet ${ }^{2}$, Florence Robaut ${ }^{1}$ \\ and Alexis Deschamps ${ }^{1, *(D)}$ \\ 1 CNRS, Grenoble INP, SIMaP, Université Grenoble Alpes, 38000 Grenoble, France; \\ imed-eddine.benrabah@grenoble-inp.fr (I.-E.B.); hugo.van-landeghem@grenoble-inp.fr (H.P.V.L.); \\ florence.robaut@grenoble-inp.fr (F.R.) \\ 2 Research, ArcelorMittal, Maizieres-les-Metz 57280, France; frederic.bonnet@arcelormittal.com \\ * Correspondence: alexis.deschamps@grenoble-inp.fr
}

Received: 22 October 2019; Accepted: 16 December 2019; Published: 18 December 2019

\begin{abstract}
In-situ high energy X-Ray diffraction (HEXRD) was used on compositionally graded steels to study the effect of substitutional elements on ferrite growth kinetics in $\mathrm{Fe}-\mathrm{C}-\mathrm{X}$ and $\mathrm{Fe}-\mathrm{C}-\mathrm{X}-\mathrm{Y}$ systems. Two systems were selected to illustrate the applicability of the combinatorial approach in studying such transformations, $\mathrm{Fe}-\mathrm{C}-\mathrm{Mn}$ and $\mathrm{Fe}-\mathrm{C}-\mathrm{Mn}-\mathrm{Mo}$. Comparison between the measured ferrite growth kinetics using HEXRD and the predicted ones using Para-Equilibrium (PE) and Local Equilibrium with Negligible Partitioning (LENP) models indicates that the fractions reached at the stasis of transformation are lower than the predicted ones. Experiments indicated a deviation of measured kinetics from both PE and LENP models when increasing Mn and decreasing Mo (in Fe-C-Mn-Mo system). The large amount of data that can be obtained using this approach can be used for validating existing models describing ferrite growth kinetics.
\end{abstract}

Keywords: high energy X-ray diffraction; combinatorial metallurgy; transformation kinetics

\section{Introduction}

In the vast majority of modern steel grades, the microstructure that imparts their properties is the product of a sequence of solid-state phase transformations. Tailoring the microstructure of those grades to further enhance their properties requires a clear understanding of the kinetics of these phase transformations and how they are influenced by processing and composition parameters. The transformation of austenite into ferrite is a prominent example of such phase transformations. It has been, and remains to this day, a central topic in the work of both the academic and the industrial steel research communities [1-9]. Quantitative modeling of this transformation is particularly challenging due to the diffusivity gap of several orders of magnitude between the fast interstitial solutes ( $\mathrm{C}$ and $\mathrm{N}$ ) and slow substitutional solutes (such as $\mathrm{Si}, \mathrm{Cr}, \mathrm{Mn}, \mathrm{Ni}$, and Mo...), especially in industrially relevant temperature conditions. Due to this difference in mobility, the transformation can proceed with negligible partitioning of the substitutional elements and the growth of the product phase happens under unknown interfacial conditions [2,10]. Two models representing the limit cases of interfacial conditions known as paraequilibrium (PE) and local equilibrium with negligible partitioning (LENP) were used in the numerous attempts at predicting the rate of this transformation $[2,3,11,12]$. For both, the results were found to agree with experiments only in different, restricted ranges of compositions and temperatures $[4,6,9,13]$. Experimental results show that the behavior exhibited by the interface 
is more complex than these limit cases. To explain this observation, it has been proposed that the interactions of solutes with the moving interface, while ignored in the two aforementioned models, lead to substantial dissipation of energy when the transformation occurs with negligible partitioning $[14,15]$. These interactions are known to exist because they lead to a compositional heterogeneity, or segregation, at the transformation interface that was experimentally measured using atom probe tomography (APT) or analytical transmission electron microscopy (TEM) [16-18]. The transport of this compositional heterogeneity during the transformation is the source of the additional dissipation termed solute drag (SD). Two different, but equivalent, formalisms were developed to express the amount of energy dissipated by solute drag $[15,19]$. This effect was integrated into a variety of models that displayed a better aptitude at predicting kinetics for broad ranges of composition and temperature in ternary systems $[13,20,21]$. One of the most notable characteristics of those models is their capability of describing the transition from PE to LENP transformation rates encountered in certain conditions. Attempts at generalizing those models to quaternary systems, containing two substitutional species, showed mixed results, which highlights the new questions they raise [22,23]. While they allow the description of complex interface behaviors, they require quantitative knowledge of thermodynamics in the interface, as a function of temperature and alloy composition [3].

The effect of alloy composition can be tackled using a combinatorial approach on compositionally-graded alloys [24]. Such materials, usually made by joining dissimilar alloys subsequently heat-treated to promote interdiffusion, enable the exploration of a multitude of compositions, leading to maps of the composition-dependence of microstructures in a single step. This methodology is being actively developed in materials science [25], both from the viewpoint of microstructures [26] and from the viewpoint of related properties [27,28]. In steels, it has been used in conjunction with optical microscopy to characterize the effect of composition on recrystallization [29] and on austenite-to-ferrite transformation [24]. Until now, the study of phase transformations on compositionally graded steels has been limited to ex-situ characterization at the end of a prescribed heat treatment. Not only do such experiments lack the in-situ nature to obtain a full kinetic record of the transformation, but, for the special case of steels, the microstructure changes drastically between the heat treatment temperature and the ex-situ observation temperature (usually room temperature). Upon cooling, the remaining austenite may transform in several products (bainite and martensite) depending on alloy composition, which makes the ex-situ analysis difficult. In the field of nanoscale precipitation, several studies have been carried out by using synchrotron X-ray in-situ techniques (small-angle X-ray scattering (SAXS)) applied on compositionally-graded alloys to access phase transformation kinetics with simultaneous time- and space-resolution $[30,31]$. This is made possible by the high flux of synchrotron sources, which enables measuring a microstructural state with sufficiently high time resolution so that the composition gradient can be continuously scanned in front of the X-ray beam to monitor the progress of the transformation in all the alloy compositions that constitute the graded sample [25]. In the case of the austenite-to-ferrite phase transformation, a fast and quantitative measurement of phase fractions can be achieved in-situ during heat treatments by using high-energy X-ray diffraction (HEXRD). In-situ experiments have been reported along complex heat treatments with time resolutions of the order of $10 \mathrm{~Hz}$, which is much faster than the typical phase transformation rates expected for isothermal austenite-to-ferrite transformations and thus should enable simultaneous time- and space-resolved measurements of the advancement of a phase transformation $[32,33]$. The aim of the present paper is to describe a complete methodology to achieve such results. The first part details the fabrication of samples with composition gradients of several substitutional species ( $\mathrm{X}$ and $\mathrm{Y}$, achieving graded quaternary $\mathrm{Fe}-\mathrm{C}-\mathrm{X}-\mathrm{Y}$ alloys), with the following requirements:

(i) The carbon content in the graded materials should be well controlled, which is made difficult by the high temperature required for the inter-diffusion heat treatment.

(ii) The spatial extension of the composition gradient should be sufficient as compared to the typical size of a synchrotron beam $(\sim 200 \mu \mathrm{m})$ so that the sample volume probed for one diffraction pattern can be considered approximately homogeneous in composition. Thus, many alloy compositions 
can be measured in a single experiment. Besides, it would also ensure that the composition gradients are sufficiently weak to not interfere with the phase transformation itself, since it will have an almost constant composition at the scale of the transformation (a few microns). Such an extension of several $\mathrm{mm}$ being difficult to achieve by inter-diffusion alone, a further step of plastic deformation is added to the process.

(iii) The grain size within the sample gradient should be sufficiently small to ensure quantitative and statistic characterization of the phase transformation from the HEXRD data. This requirement is facilitated by the cold plastic deformation step, which results in recrystallization upon heating at the beginning of the in-situ heat treatment. However, this condition has only been partly achieved in the present study, which points towards some possible improvements in future work.

The second part reports on the practical implementation of the in-situ synchrotron measurements and on preliminary results obtained at the European synchrotron ESRF. These results are discussed in the context of the existing literature and models. Potential artifacts affecting them are also examined to plan future improvements of the method.

\section{Preparation of Compositionally Graded Alloys}

The methodology of fabrication of diffusion multiples consists in three steps, as shown in Figure 1: solid state diffusion bonding using uniaxial hot compression, high temperature diffusion to generate gradients of composition, and finally cold rolling to extend the composition profiles. Since the aim of this study was to explore the effect of substitutional elements on ferrite growth in steels, the diffusion multiples should contain gradients of composition for the substitutional elements with (ideally) a constant carbon content.

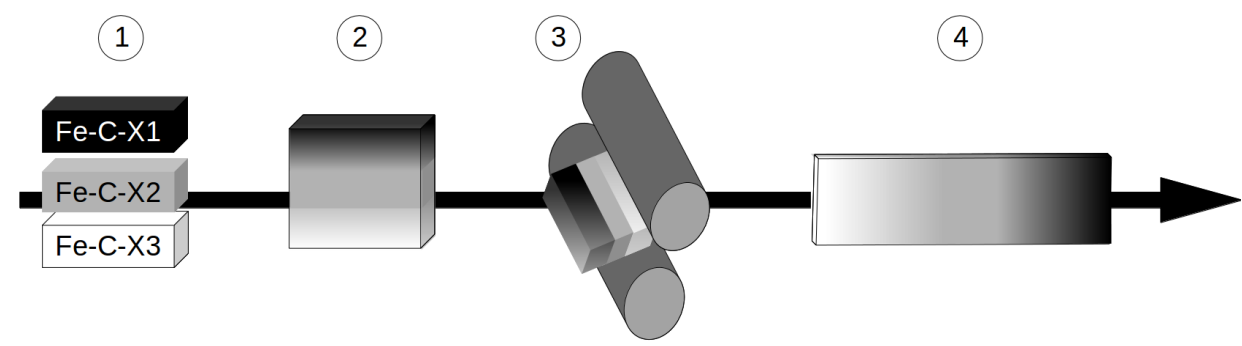

Figure 1. Schematic illustration of the different steps for making materials with macroscopic gradients of composition: (1) uniaxial hot compression; (2) high temperature diffusion treatment; (3) cold rolling; and (4) recrystallization treatment.

Samples of dimensions $15 \mathrm{~mm} \times 15 \mathrm{~mm} \times 7 \mathrm{~mm}$ were prepared from one binary alloy Fe- $0.27 \mathrm{C}$ (all compositions are given in wt. \%) and five ternary alloys Fe- $0.27 \mathrm{C}-\mathrm{X}(\mathrm{X}: 1.0 \mathrm{Mn}, 0.2 \mathrm{Mo}$ or $1.0 \mathrm{Ni})$. These alloys were supplied by ArcelorMittal, Maizieres-les-Metz, France, and their precise initial composition is provided in Table 1. As depicted in Figure 1, multiples of three samples were made of different alloys with different compositions. To this end, both surfaces of the central sample and one surface of each side sample were polished to $1 \mu \mathrm{m}$ finish using standard metallographic techniques. Solid-state bonding between different alloys was achieved using hot uniaxial compression, during which the samples were held together under a compressive stress of $20 \mathrm{MPa}$ at $900{ }^{\circ} \mathrm{C}$ for $1 \mathrm{~h}$ using a custom-made compression device. To avoid high temperature oxidation, the samples were wrapped in tantalum foil and the joining operation was conducted under a controlled atmosphere using $\mathrm{Ar} / 2 \% \mathrm{H}_{2}$ gas as at reduced pressure ( 5 mbar).

An example of a diffusion multiple made of 3 samples (Fe-C-Ni, $\mathrm{Fe}-\mathrm{C}-\mathrm{Mo}$ and $\mathrm{Fe}-\mathrm{C}-\mathrm{Mn}$ ) is shown in Figure 2. At the end of the compression experiments, interfaces between different alloys were analyzed using optical microscopy and scanning electron microscopy (SEM). Figure 3a shows an example of SEM micrograph of the interfaces of a multiple between two different ternary alloys, 
of composition $\mathrm{Fe}-\mathrm{C}-\mathrm{Mn}$ and $\mathrm{Fe}-\mathrm{C}-\mathrm{Mo}$. The observations show that the interfaces are free of porosities or secondary phases such as oxides or nitrides. In certain cases, grains grow across the interface to the point that it can no longer be distinguished in the microstructure between a binary $\mathrm{Fe}-\mathrm{C}$ and a ternary $\mathrm{Fe}-\mathrm{C}-\mathrm{Mo}$ interface, as shown in Figure $3 \mathrm{~b}$.

Table 1. Chemical composition (wt. \%) of the different alloys used to make diffusion multiples

\begin{tabular}{ccccccccc}
\hline Composition wt. $\%$ & C & Si & Mn & Mo & Cr & Ni & Al & Other Alloying Elements \\
\hline Fe-C & 0.27 & 0.03 & $<0.002$ & $<0.002$ & $<0.002$ & $<0.002$ & 0.003 & $<0.002$ \\
\hline Fe-C-Mn & 0.27 & 0.03 & 0.98 & $<0.002$ & $<0.002$ & $<0.002$ & 0.003 & $<0.002$ \\
\hline Fe-C-Mo & 0.27 & 0.02 & 0.004 & 0.21 & $<0.002$ & $<0.002$ & 0.003 & $<0.002$ \\
\hline Fe-C-Ni & 0.27 & 0.02 & 0.004 & $<0.002$ & $<0.002$ & 1.0 & 0.003 & $<0.002$ \\
\hline
\end{tabular}

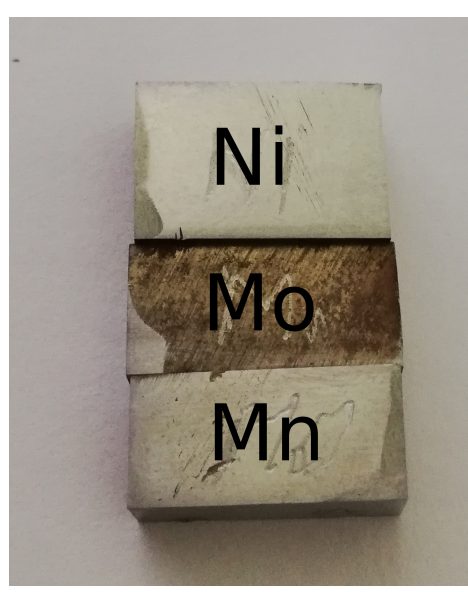

Figure 2. Diffusion multiple between three ternary alloys, a Fe-C-Ni, a Fe-C-Mo, and a Fe-C-Mn.
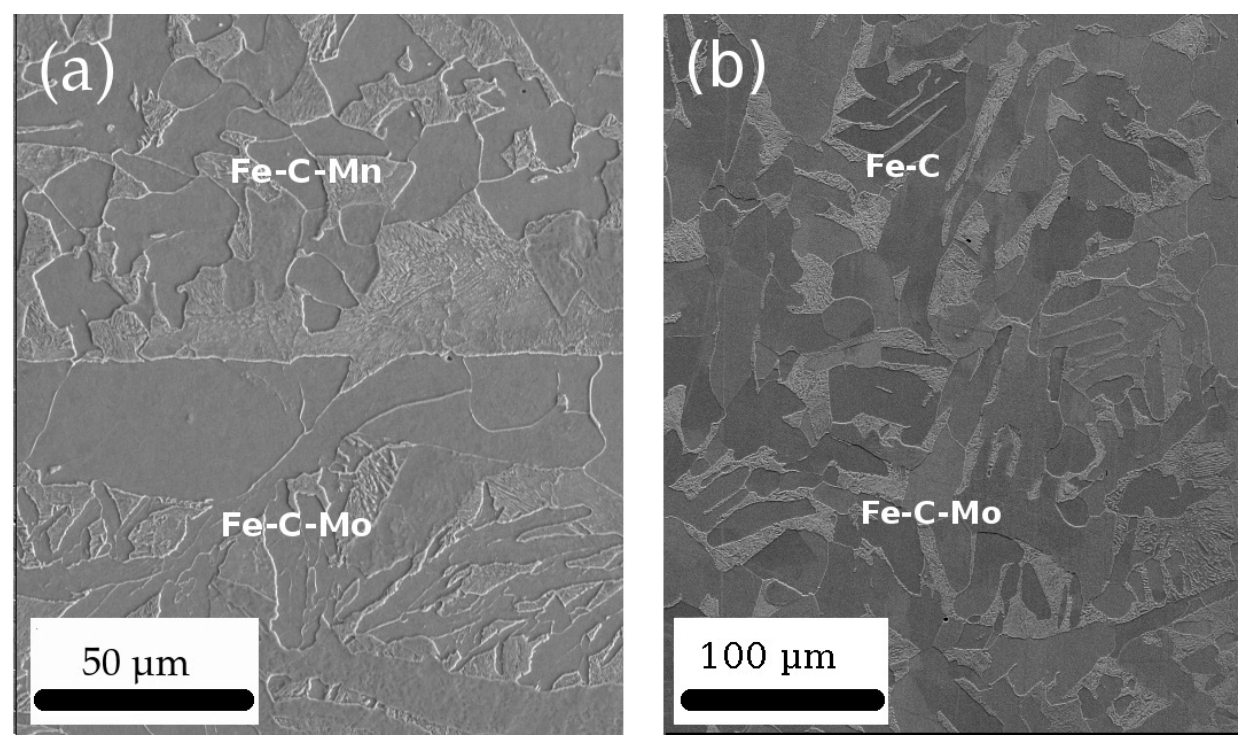

Figure 3. Secondary electron micrograph of a junction between: (a) two ternary Fe-C-Mn and Fe-C-Mo alloys; and (b) one binary Fe-C and one ternary Fe-C-Mo alloys. The interfaces are free of pores and secondary phases. In the case of the $\mathrm{Fe}-\mathrm{C} / \mathrm{Fe}-\mathrm{Mo}-\mathrm{C}$ interface, the austenite grains have grown across the interface, which is no longer visible using secondary electrons.

The next step consisted in generating gradients of composition using diffusion at high temperature. To avoid composition discontinuities, diffusion should be performed in a single-phase domain. Calculations using the Mob2 database from Thermocalc software [34] suggested that a treatment 
at $1380{ }^{\circ} \mathrm{C}$ ( $\gamma$ phase) during $72 \mathrm{~h}$ should result in gradients width of $600-900 \mu \mathrm{m}$ depending on the diffusing element. Controlling the atmosphere during this step is of paramount importance to prevent oxidation or decarburization of the sample. Diffusion treatments were conducted under primary vacuum with a continuous flow of argon (of high purity-oxygen less than $5 \mathrm{ppb}$ ). The pressure of the furnace chamber was $0.5 \mathrm{mbar}$ with an argon flow of $0.5 \mathrm{~L} / \mathrm{min}$. Titanium shavings were added to further reduce oxygen content in the furnace and prevent unwanted oxidation or decarburization. At the end of this step, diffusion multiples were cooled in the furnace and held at $650{ }^{\circ} \mathrm{C}$ for $8 \mathrm{~h}$ to obtain a sufficiently ductile microstructure for the subsequent plastic deformation step.

Electron probe microanalysis (EPMA) measurements were used to characterize the obtained concentration profiles. Measurements were carried out using a CAMECA SX50 electron microprobe with an accelerating voltage of $15 \mathrm{kV}$ and a beam current of $900 \mathrm{nA}$. Samples were polished to $1 \mu \mathrm{m}$ using standard metallographic techniques, followed by a final polishing using an alumina suspension. To avoid surface contamination which can affect carbon content measurements, carbon standards ( $\mathrm{Fe}-\mathrm{C}$ samples with various $\mathrm{C}$ contents) were polished along with the samples, right before their introduction into the analysis chamber. Furthermore, a liquid nitrogen cooling trap and a low-pressure oxygen jet were used to reduce carbon contamination. An analytical procedure based on the calibration curve method was used for the quantification of carbon [35]. This method consists in measuring the $\mathrm{C} \mathrm{K} \alpha$ intensity at the maximum of the peak as a function of carbon content for different standards. For the samples to be analyzed, carbon content is determined assuming a linear relationship between the measured C K $\alpha$ intensity and carbon concentration [35].

Figure 4a shows an example of composition profiles between Fe-C-Mn and Fe-C-Mo before and after high temperature treatment. Results show concentration profiles of $\sim 950 \mu \mathrm{m}$ (for Mn) and $700 \mu \mathrm{m}$ (for Mo) after diffusion. Composition gradients were generated for all the possible ternary systems (using $\mathrm{Fe}-\mathrm{C}$ and $\mathrm{Fe}-\mathrm{C}-\mathrm{X}$ couples) and quaternary systems (using $\mathrm{Fe}-\mathrm{C}-\mathrm{X} 1$ and $\mathrm{Fe}-\mathrm{C}-\mathrm{X} 2$ ). The main target of making diffusion multiples in the present case was to measure the austenite-to-ferrite transformation kinetics as a function of composition using in situ synchrotron X-ray diffraction. Since the characteristic dimension of ferrite growth reaction is $10-100 \mu \mathrm{m}$, a $600-900 \mu \mathrm{m}$ diffusion zone is not suitable to achieve accurate investigation of composition effect on austenite-to-ferrite phase transformation. For this reason, the composition profiles were extended above the millimeter scale using cold rolling. To obtain homogeneous deformation, diffusion multiples were mounted into a block of low-carbon steel and the whole assembly was cold-rolled with multiple small passes to avoid sample damage. The thickness of diffusion couples was reduced by $85 \%$, from 7 to $1 \mathrm{~mm}$. This step was followed by a heat treatment at $900{ }^{\circ} \mathrm{C}$ for $5 \mathrm{~min}$ followed by water quenching to homogenize the carbon distribution in the microstructure and to recrystallize the sample and obtain small grains, so that the diffraction patterns obtained using X-ray experiments would approach continuous Debye-Scherrer rings.

After the cold rolling step, the new composition profiles were measured using EPMA. Figure 4a compares the composition gradients after diffusion treatment and after cold rolling for a diffusion couple between $\mathrm{Fe}-\mathrm{C}-\mathrm{Mn}$ and $\mathrm{Fe}-\mathrm{C}-\mathrm{Mo}$. The concentration profiles went from $950 \mu \mathrm{m}$ for $\mathrm{Mn}$ to $6.6 \mathrm{~mm}$ and from $600 \mu \mathrm{m}$ for Mo to $4.2 \mathrm{~mm}$ after cold rolling. Another example of diffusion couple between $\mathrm{Fe}-\mathrm{C}$ and $\mathrm{Fe}-\mathrm{C}-\mathrm{Ni}$ is shown in Figure $4 \mathrm{~b}$. One can notice that the carbon content is constant across the diffusion couple. In some cases, due to the influence of substitutional content on the chemical potential of carbon, a gradient of carbon concentration exists; however, it remains of small magnitude, at most $0.025 \% \mathrm{wt} \cdot \mathrm{mm}^{-1}$ in case of $\mathrm{Cr}$ containing couples. This gradient does not interfere with the interpretation of the data since any further modeling compared against it takes into account the carbon content measured locally by EPMA. The obtained gradient lengths are sufficiently extended to allow recording time-resolved measurements at many compositions over the gradient using a synchrotron beam size of $\sim 200 \mu \mathrm{m}$. Moreover, the composition profiles are continuous and without local fluctuations which makes the HEXRD measurements more accurate. 

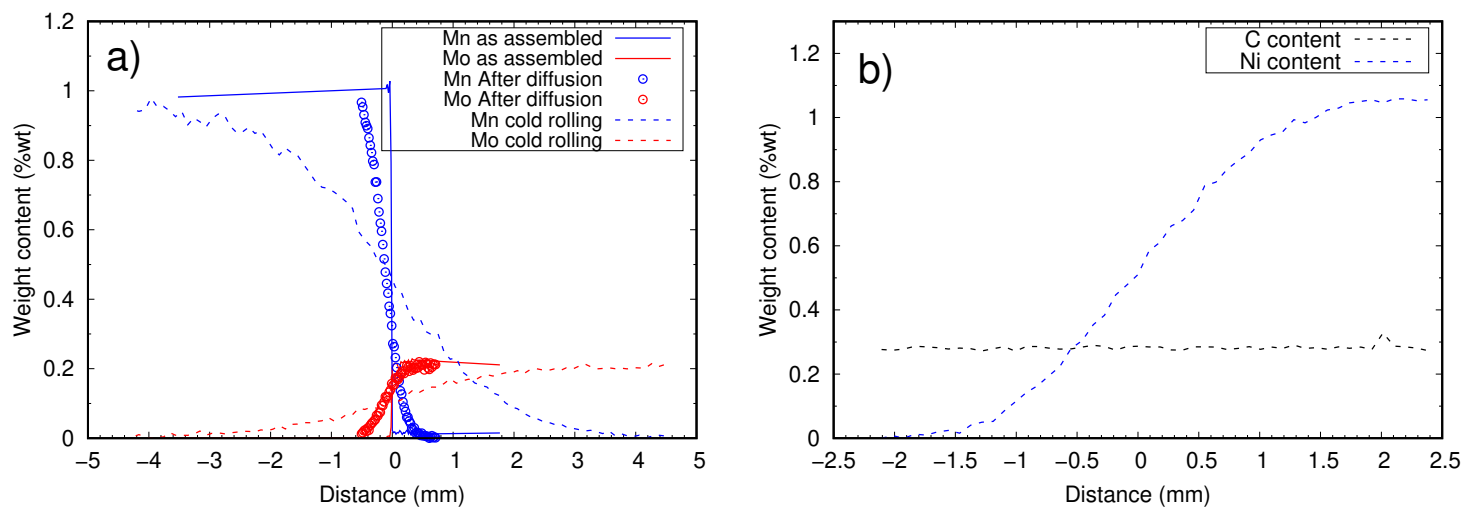

Figure 4. (a) Measured composition profiles using EPMA in substitutional alloying element across $\mathrm{Fe}-0.26 \mathrm{C}-1 \mathrm{Mn} / \mathrm{Fe}-0.26 \mathrm{C}-0.2 \mathrm{Mo}$ (wt.\%) interface, as assembled (line), after the diffusion treatment (circles) and after cold rolling (dashed lines). (b) Carbon and nickel weight contents as function of distance measured after cold rolling in a Fe-0.26C/Fe-0.26C-1Ni (wt.\%) diffusion couple.

\section{High Energy X-Ray Diffraction Experiments}

\subsection{Methodology}

The in-situ High energy X-ray diffraction experiments were performed at the beamline ID11 of the European Synchrotron Radiation Facility (ESRF) in Grenoble, France, using an energy of $87 \mathrm{keV}$ $(\lambda=0.4125 \AA$ ). The high-energy beam allows working in transmission diffraction mode. To maximize the number of grains in the illuminated volume, a beam size of $0.6 \times 0.2 \mathrm{~mm}^{2}(0.2 \mathrm{~mm}$ in the direction of the concentration gradient, $0.6 \mathrm{~mm}$ in the perpendicular direction) was used. The austenite grain size after the heat treatment of $5 \mathrm{~min}$ at $900{ }^{\circ} \mathrm{C}$ was measured to be about $50 \mu \mathrm{m}$. The Debye-Scherrer diffraction rings were collected using a high-resolution 2D FReLoN CCD detector with a high acquisition rate $(5 \mathrm{~Hz})$ placed at $0.260 \mathrm{~m}$ from the sample. Diffusion couples with dimensions of $10 \mathrm{~mm} \times 6-8 \mathrm{~mm} \times 1 \mathrm{~mm}$ were heated using an INSTRON electro-thermal mechanical set-up (ETMT). Heating was performed by passing a current through the sample (Ohmic heating) and the temperature was regulated using a spot-welded Type-S thermocouple. Since temperature gradients exist within the sample due to the water-cooled grips holding them, samples were mounted in a way that the composition gradient was perpendicular to the temperature gradient, as shown in Figure 5. From thermal modeling, we expect a maximum temperature deviation within the beam size of $3{ }^{\circ} \mathrm{C}$. An argon flow was used to limit the decarburization and oxidation during the experiments. Prior to each experiment, the top surface of the sample was scanned horizontally by the X-ray beam to find out precisely the location of the control thermocouple and thus ensure that the control temperature is effectively that of the sample hit by the X-rays. To gather time- and space-resolved ferrite growth kinetics during heat treatments, the compositionally graded samples were translated along the composition gradient. The samples were translated over 3-8 $\mathrm{mm}$ (depending on the gradient length of each sample) using the vertical motor of the beamline that allows a maximum speed of $0.385 \mathrm{~mm} \cdot \mathrm{s}^{-1}$. The acquisition time was $0.156 \mathrm{~s}$ and diffraction patterns were recorded every $75 \mu \mathrm{m}$. Using this configuration, we were able to record diffraction patterns every 10-30 s (depending on the gradient length) for each composition along the gradient.

The details of the heat treatments for in-situ HEXRD experiments were as follows. The compositionally graded samples were heated to $910{ }^{\circ} \mathrm{C}$ at $30{ }^{\circ} \mathrm{C} / \mathrm{s}$ and held $10 \mathrm{~s}$ at this temperature to reach full austenitization, which was checked using the diffraction patterns recorded during this step. Samples were then rapidly cooled down at $80{ }^{\circ} \mathrm{C} / \mathrm{s}$ to an inter-critical temperature $\left(730{ }^{\circ} \mathrm{C}\right.$, $750{ }^{\circ} \mathrm{C}, 762{ }^{\circ} \mathrm{C}$, and $775^{\circ} \mathrm{C}$ ) and held $20 \mathrm{~min}$ at this temperature to follow austenite-to-ferrite phase transformation. Finally, samples were quenched to room temperature at $80{ }^{\circ} \mathrm{C} / \mathrm{s}$. The obtained Debye-Scherer diffraction rings (Figure 6a) were converted to classical intensity $-2 \theta$ diffraction 
spectra (Figure 6b) by circular integration using pyFAI software. Rietveld refinement was used to calculate phase fractions using the FullProf software. A pseudo-Voigt function was used to model the experimental diffraction peaks and a total of 22 parameters were used for Rietveld adjustment, such as scale and shape factors, temperature effect, lattice parameters, and asymmetry factors. However, the obtained 2D diffraction patterns contained some saturated pixels due to the presence of some coarse grains in the microstructure. As a result, some intensity was lost due to saturation close to the peak maxima, resulting in a comparatively higher intensity in the peak tails, so that the measured diffraction peaks appeared shouldered. This artifact made Rietveld adjustment more difficult and resulted in errors on the calculated phase fractions. Figure 7 shows an example of a shouldered peak and the calculated peak using Rietveld adjustment. In addition, Rietveld refinement is not suitable for low volume fractions such as encountered at the beginning or at the end of the transformation. As an alternative, we used an integration method to evaluate the area of isolated peaks corresponding to the two phases, FCC-austenite (200, 211, and 321) and BCC-ferrite (200, 211, and 211). A linear interpolation was used to extract the background noise and the individual peaks were integrated using the trapezoidal method. The volume fraction of ferrite $f_{\alpha}$ was estimated from the integrated intensity of the monitored austenite $\left(I_{\gamma}, i\right)$ and ferrite $\left(I_{\alpha}, i\right)$ :

$$
f_{\alpha}=\frac{\frac{1}{N} \sum_{i=1}^{N}\left(\frac{I_{\alpha, i}}{R_{\alpha, i}}\right)}{\frac{1}{N} \sum_{i=1}^{N}\left(\frac{I_{\alpha, i}}{R_{\alpha, i}}\right)+\frac{1}{M} \sum_{i=1}^{M}\left(\frac{I_{\gamma, i}}{R_{\gamma, i}}\right)}
$$

where $N$ and $M$ are the number of considered ferrite and austenite reflections, respectively. The index $i$ refers to the $h k l$ reflection of interest. The normalization factors for the austenite $R_{\gamma, i}$ and ferrite $R_{\alpha, i}$ peak intensities were extracted from the ICCD files (international centre for diffraction data).

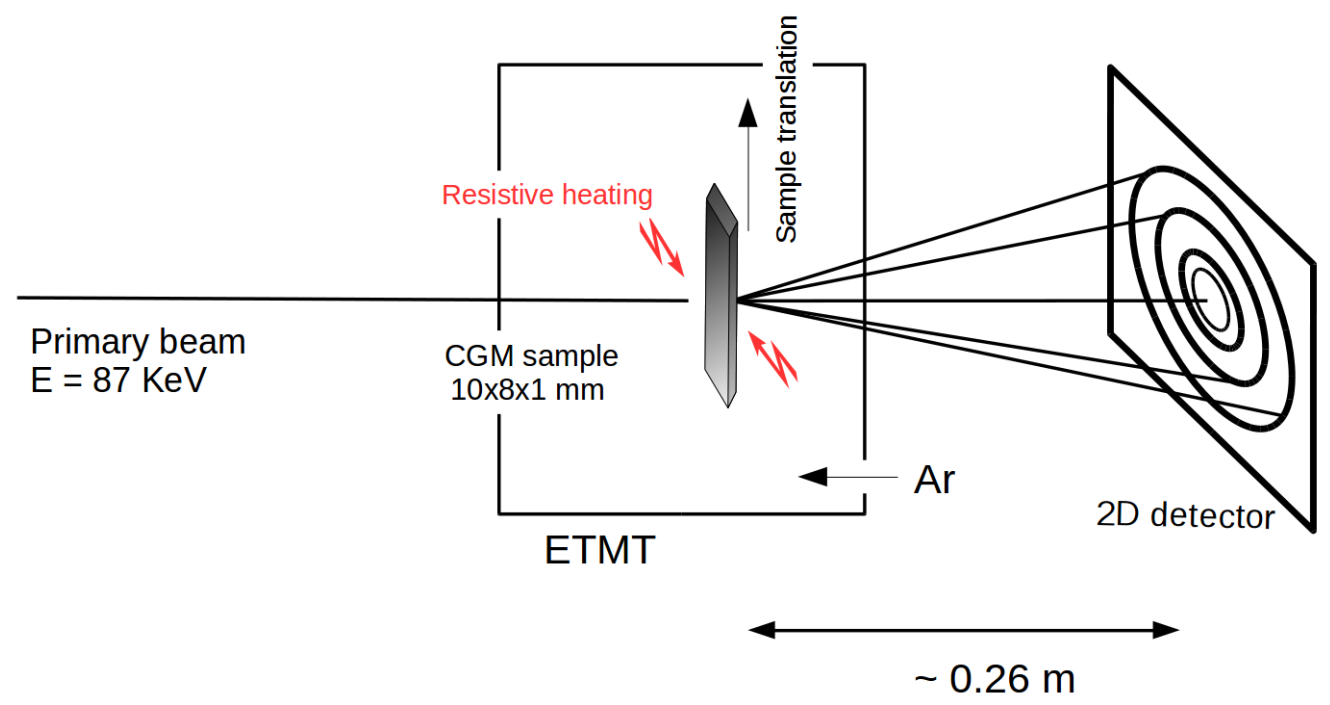

Figure 5. Sketch of the experimental setup used for HEXRD experiments. The compositionally graded sample was translated along the composition gradient in $\mathrm{Z}$ direction to avoid temperature gradient caused by the water cooled clamps.

To test the validity of the numerical method, a comparison between the calculated ferrite fraction using Rietveld refinement and the numerical integration was carried out on samples where the obtained diffraction patterns were free of shouldered peaks. Good agreement was found between the predicted ferrite fraction using the two methods, as the absolute measurement discrepancy on the ferrite fraction was $10 \%$ in the worst case. 
a)
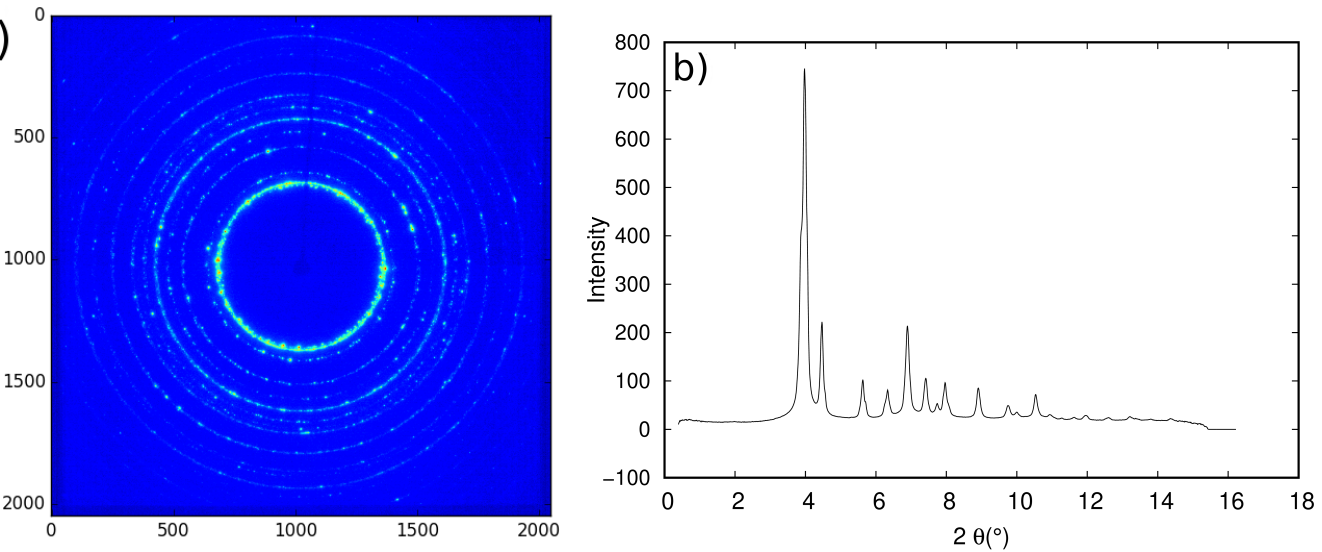

Figure 6. (a) Debye-Scherer diffraction rings obtained from HEXRD experiments; and (b) integrated $1 \mathrm{D}$ diffractogram (intensity vs. $2 \theta$ ).

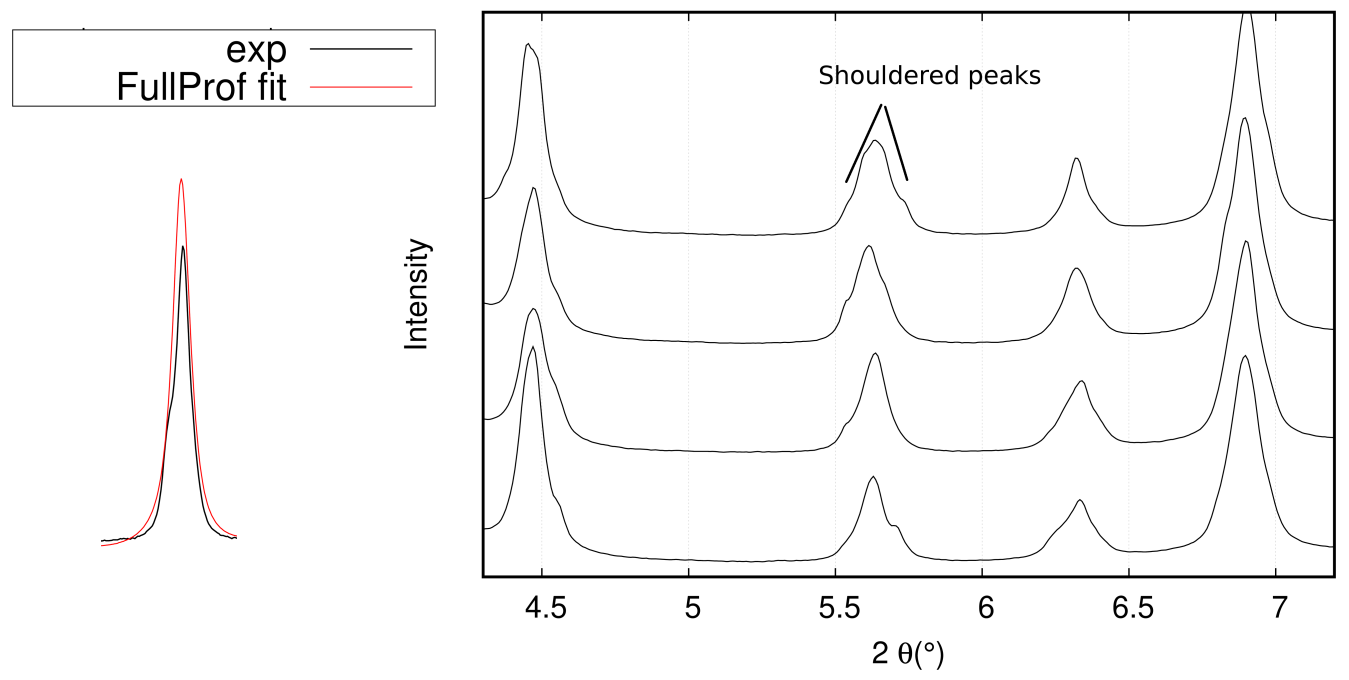

Figure 7. Integrated 1D diffractogram (intensity vs. $2 \theta$ ) showing the shouldered peaks due to the coarse microstructure and the resulting error on the Reitvield adjustement.

\subsection{Results}

Figure 8 shows an example of the evolution of diffraction patterns for one composition (0.15C-0.65Mn-0.06Mo (wt.\%)) of the diffusion couple Fe-0.16C-1Mn/Fe-0.16C-0.2Mo during different steps of the thermal cycle. At room temperature, before in-situ experiment, the microstructure is fully martensitic and only BCC-phase peaks are present on diffraction patterns. At $910{ }^{\circ} \mathrm{C}$, only FCC-phase corresponding to austenite is observed which confirm the complete austenitization of the material microstructure at this temperature. After cooling to the inter-critical temperature $\left(730^{\circ} \mathrm{C}\right)$, both phases are observed on diffraction patterns with variable intensities during holding. Monitoring the integrated intensities of ferrite and austenite peaks during the holding step provides the phase volume fraction evolution.

The data obtained for the special case of a gradient in $\mathrm{Mn}$ at constant carbon content are now presented in more detail. A diffusion couple of $\mathrm{Fe}-0.16 \mathrm{C} / \mathrm{Fe}-0.16 \mathrm{C}-1 \mathrm{Mn}$ (wt. $\%$ ) was austenitized at $910^{\circ} \mathrm{C}$, quenched to $760{ }^{\circ} \mathrm{C}$ and held at this temperature for $20 \mathrm{~min}$. Figure 9 shows the $\mathrm{Mn}$ profile as function of position superposed to the corresponding measured ferrite fraction by HEXRD at the end of the isothermal step (i.e., after $20 \mathrm{~min}$ ). The Mn content varies from 0 (\%wt.) to 1 (\%wt.) over a distance of $8 \mathrm{~mm}$. If we consider a beam size of $200 \mu \mathrm{m}$ as used in the HEXRD experiments, the variation of 
composition within the beam is of $0.025 \mathrm{Mn}(\% \mathrm{wt}$.). The corresponding formed ferrite fraction shows a transition from high fractions $(\sim 80 \%)$ at low Mn content to low ferrite fractions $(\sim 20 \%)$ at high Mn content (1\%wt.). Figure 10 illustrates an isothermal section of the $\mathrm{Fe}-\mathrm{C}-\mathrm{Mn}$ at $760^{\circ} \mathrm{C}$ calculated using TCFE9 database of ThermoCalc, showing the different growth modes for the composition range of the diffusion couple. It can be seen that, for the whole composition gradient, both LENP or PE are theoretically possible transformation modes. The predicted ferrite fraction using PE and LENP modes after $20 \mathrm{~min}$ at $760^{\circ} \mathrm{C}$ are represented in Figure 9. LENP and PE calculations were carried using DICTRA software and TCFE9 and Mob2 databases. A spherical $50 \mu \mathrm{m}$ grain size was used, which is representative of the real microstructure.
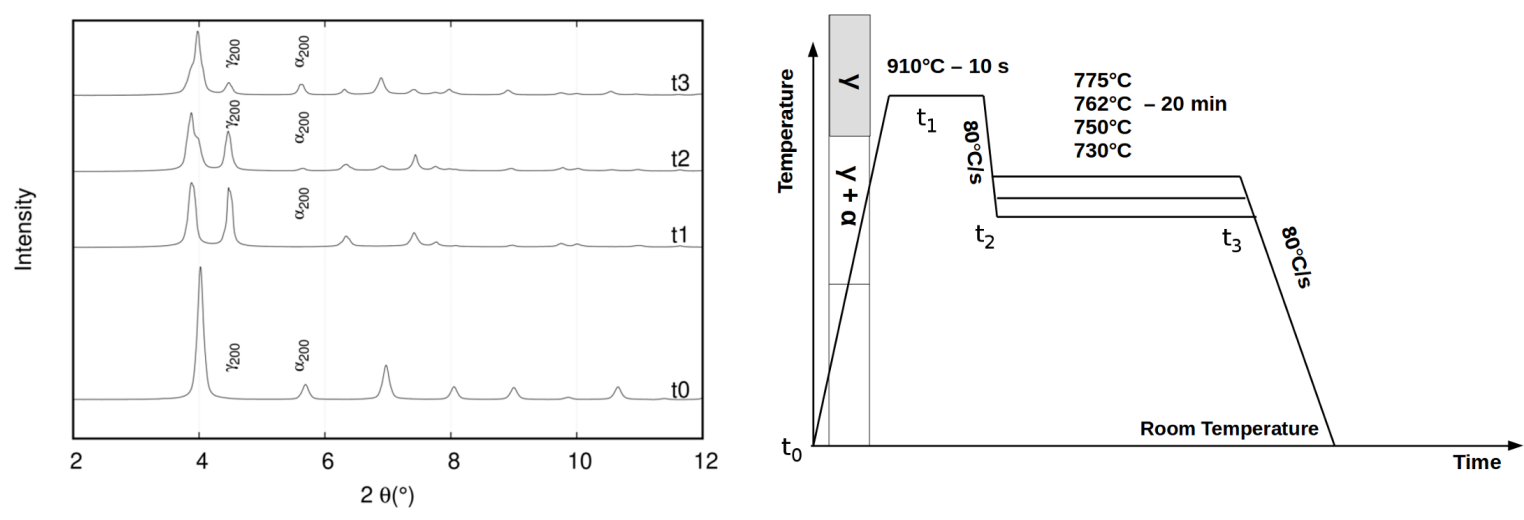

Figure 8. Evolution of diffraction patterns during a thermal treatment at different times, corresponding to one composition of a diffusion couple of $\mathrm{Fe}-0.16 \mathrm{C}-1 \mathrm{Mn} / \mathrm{Fe}-0.16 \mathrm{C}-0.2 \mathrm{Mo}$. $\mathrm{t}_{0}$, austenization at $910^{\circ} \mathrm{C}$; $t_{1}$, beginning of isothermal holding at $760{ }^{\circ} \mathrm{C}$; $t_{2}$, at the end of isothermal holding; $t_{3}$, after quenching to room temperature.

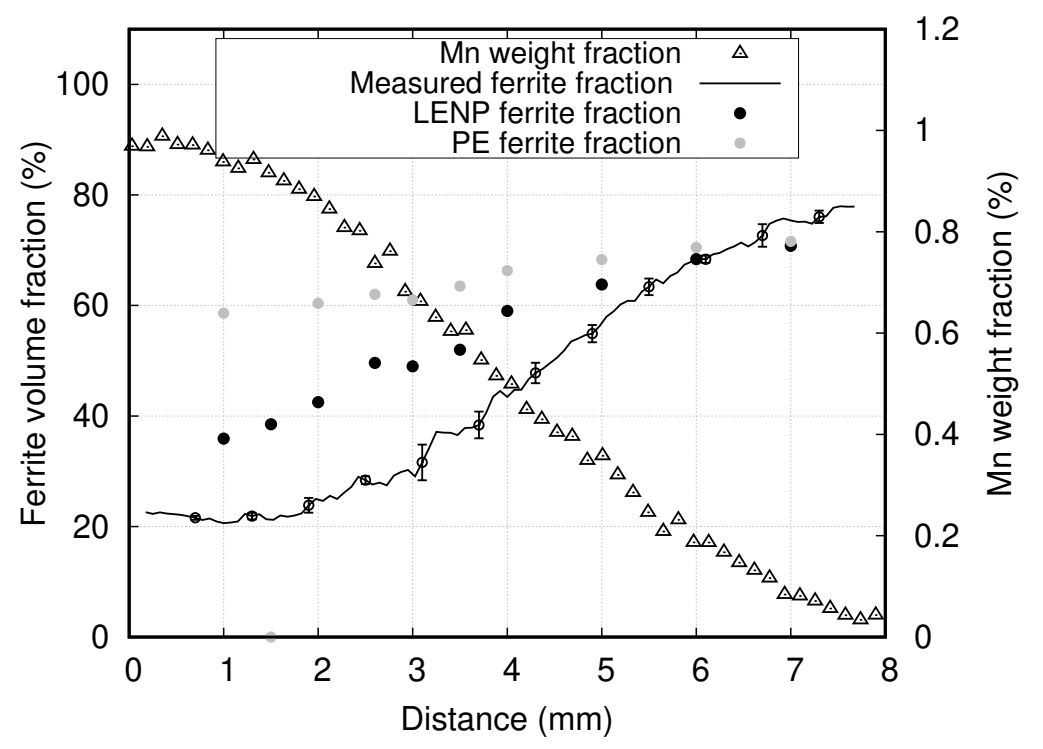

Figure 9. Measured ferrite fractions using HEXRD experiments (solid line) within the Mn concentration gradient of the diffusion couple austenitized at $900{ }^{\circ} \mathrm{C}$ for $10 \mathrm{~min}$ and quenched to $760{ }^{\circ} \mathrm{C}$ for $20 \mathrm{~min}$. The plotted fractions correspond to the end of the isothermal step at $760{ }^{\circ} \mathrm{C}$. The calculated ferrite fractions using LENP (black circles) and PE (gray circles) models for different Mn compositions are superimposed. The error bars represent the local fluctuation of ferrite fraction. 


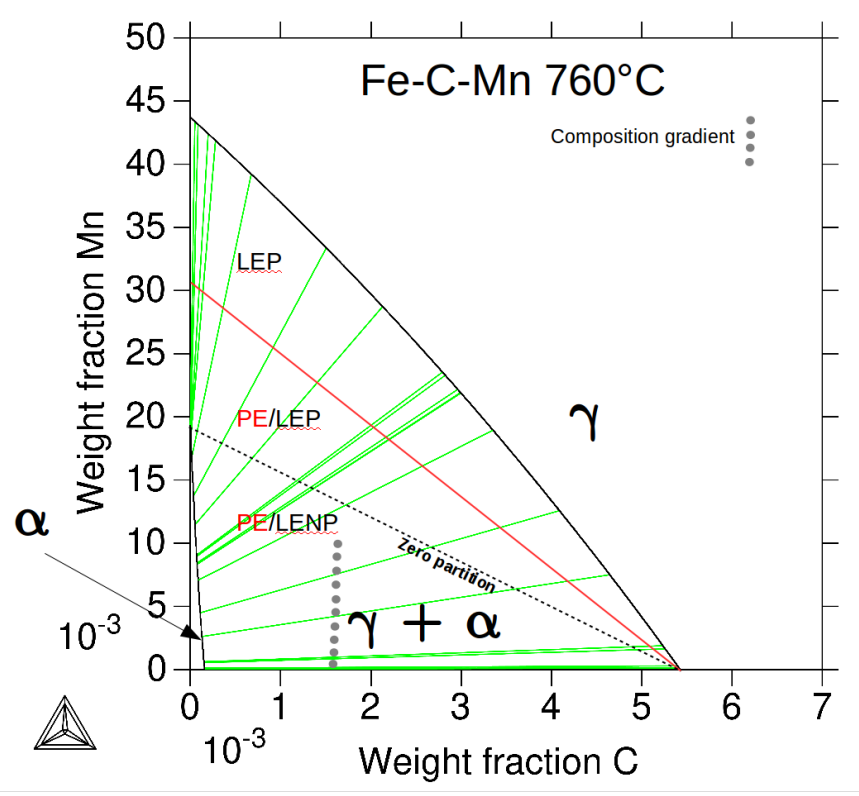

Figure 10. Isothermal section of the $\mathrm{Fe}-\mathrm{C}-\mathrm{Mn}$ at $760{ }^{\circ} \mathrm{C}$ showing the different growth modes (LEP-LENP and PE) for the composition range of the diffusion couple (gray circles).

At low Mn content, the measured ferrite fraction is comparable to the predicted one using both PE and LENP models, which differs little from the equilibrium fraction. As Mn concentration increases, the measured ferrite fraction becomes lower than both PE and LENP predictions. Both PE and LENP modes consider that ferrite formation is controlled by carbon diffusion in austenite but with different assumptions at the interface. They represent the thermodynamic limits of non-partitioned growth. In LENP, local equilibrium of the substitutional element is maintained at the interface by a solute spike. $\mathrm{PE}$, on the other hand, considers that substitutional elements are completely immobile and equilibrium is satisfied for carbon only $[2,3,10]$.

Another example illustrating the effect of $\mathrm{Mn}$ and Mo content on the formed ferrite fraction is shown in Figure 11. In this case, the diffusion couple of $\mathrm{Fe}-\mathrm{C}-\mathrm{Mn} / \mathrm{Fe}-\mathrm{C}-\mathrm{Mo}$ was austenitized at $900{ }^{\circ} \mathrm{C}$, quenched at $730^{\circ} \mathrm{C}$, and held at this temperature during $20 \mathrm{~min}$. The profile gradients of $\mathrm{Mn}$ and Mo as well as the corresponding measured ferrite fraction at the end of the isothermal step are plotted in Figure 11. Mn and Mo contents vary from $1 \%$ to $0 \%$ and from $0 \%$ to $0.2 \%$ (wt. $\%$ ), respectively, over a distance of $6 \mathrm{~mm}$ with a constant carbon concentration of $0.16 \%$. Low ferrite fraction $(\sim 35 \%)$ is measured at low Mo/high Mn content ( $1 \% \mathrm{Mn}$ and $0 \% \mathrm{Mo})$; the ferrite fraction increases with increasing Mo content and decreasing Mn content to reach $\sim 75 \%$ at the Mo rich/Mn lean side of the diffusion couple $(0.2 \% \mathrm{Mo}-0 \% \mathrm{Mn})$. Ferrite fraction evolution shows some irregularities due to the presence of some coarse grains that affect the diffraction patterns and thus introduce an error on the integrated peaks. This error can also originate from a decarburization process during isothermal holding. A layer of ferrite was observed at the surface of the sample after the HEXRD experiments. However, the large size of the observed ferrite due to decarburization $(>100 \mu \mathrm{m})$ means that these large volumes are less likely to contribute to the diffraction pattern given the requirement for them to be in Bragg position. If they happen to be in such a position, they contribute spots that saturate the detector locally, leading in turn to shouldering on the integrated profiles.

The last two examples illustrate the effect of composition on the formed ferrite fraction at a given temperature and time. The use of HEXRD gives access to time- and space-resolved kinetics of ferrite growth during precipitation experiments. Figure 12 shows the evolution of ferrite fraction measured using HEXRD as a function of time and position (composition) along a diffusion couple between $\mathrm{Fe}-0.16 \mathrm{C}-1 \mathrm{Mn}$ and $\mathrm{Fe}-0.16 \mathrm{C}-0.2 \mathrm{Mo}$ (\%wt.). The composition variation within the $\mathrm{X}$-ray beam in this case was $\pm 0.02 \mathrm{Mn}$ and $\pm 0.004 \mathrm{Mo}$ (\%wt.). The effects of $\mathrm{Mn}$ and Mo content on ferrite growth kinetics 
are clearly illustrated by the obtained dataset using HEXRD experiments. Ferrite growth rates, as well as the ferrite fraction reached at the plateau, increase with increasing Mo content (and decreasing Mn content). This dependency of ferrite growth rate on Mn and Mo compositions was obtained using one single experiment, which illustrates the importance of high-throughput methods on providing rich databases that can be used to understand phase transformation kinetics in steels.

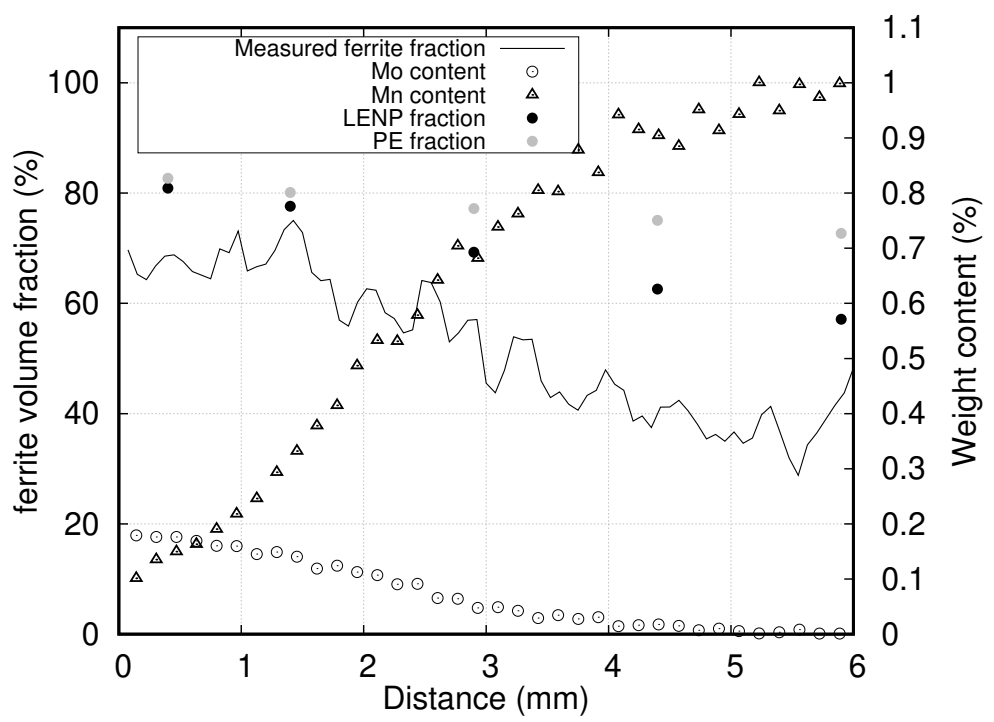

Figure 11. Measured ferrite fractions using HEXRD experiments (solid line) along the diffusion couple of Fe-C-Mn/Fe-C-Mo austenitized at $900{ }^{\circ} \mathrm{C}$ for $10 \mathrm{~min}$ then quenched to $730{ }^{\circ} \mathrm{C}$ for $20 \mathrm{~min}$. The calculated ferrite fractions using LENP (black circles) and PE (gray circles) models for different Mn and Mo compositions are superimposed.

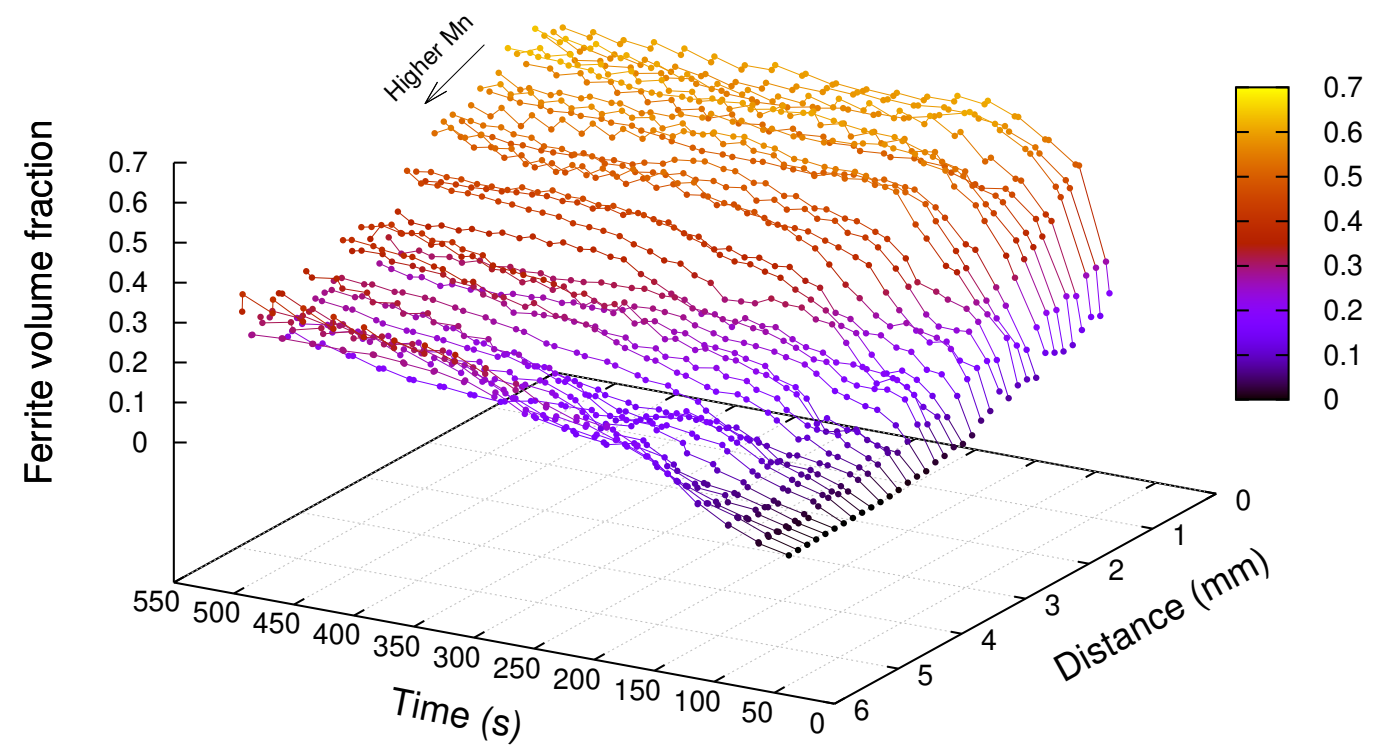

Figure 12. Evolution of ferrite fraction measured using HEXRD as a function of time and distance (composition) along a diffusion couple between Fe-0.16C-1Mn and Fe-0.16C-0.2Mo (\%wt.). The diffusion couple was austenitized at $900{ }^{\circ} \mathrm{C}$ for $10 \mathrm{~min}$ then quenched to $730{ }^{\circ} \mathrm{C}$ for $20 \mathrm{~min}$. The $\mathrm{Mn}$ and Mo content evolution as a function of distance is shown in Figure 11.

To have a better understanding of the effect of Mn and Mo contents on ferrite growth kinetics, comparisons were made between the measured fractions using HEXRD and the predicted kinetics using both PE and LENP models for a series of compositions (Figure 13a-d). The following compositions 
were chosen: Fe-0.16C-0.3Mn-0.14Mo, Fe-0.16C-0.65Mn-0.06Mo, Fe-0.16C-0.88Mn-0.015Mo, and Fe-0.16C-0.96Mn-0.001Mo (\%wt.).

The time $\mathrm{t}=0 \mathrm{~s}$ corresponds to the beginning of the isothermal step at $730^{\circ} \mathrm{C}$. The ferrite growth rate is parabolic at the beginning and tends toward a plateau of practically constant ferrite fraction. The predicted kinetics using both PE and LENP models for the same compositions are superimposed on the same figures (Figure 13a-d). For all compositions, the measured transformation rates are slower than both LENP and PE predictions and the plateau fractions are smaller than the calculated ones. In the case of high Mo content and low Mn content (Fe-0.14C-0.15Mn-0.18Mo, Figure 13a), measured kinetics are comparable to the calculated ones using PE and LENP at short times (up to $80 \mathrm{~s}$ ) and get slower and diverge from PE and LENP at longer times. The predicted ferrite fractions ((PE $(82 \%)$ and LENP $(81 \%))$ at the plateau are higher than the measured one $(65 \%)$. With increasing Mn content and decreasing Mo content (Fe-0.15C-0.3Mn- $0.14 \mathrm{Mo}$, Figure $13 \mathrm{~b}$ ), the measured transformation rate deviates from the predicted kinetics (LENP $(20 \%)$ or PE $(78 \%)$ ) after $30 \mathrm{~s}$ and the gap between the predicted fraction at the plateau and the measured one increases (59\%). The same trend is observed in Figure $13 \mathrm{c}(\mathrm{Fe}-0.16 \mathrm{C}-0.65 \mathrm{Mn}-0.06 \mathrm{Mo})$ and Figure $13 \mathrm{~d}$ (Fe-0.16C-0.88Mn-0.015Mo), the difference between the measured and the predicted kinetics becomes more pronounced, as is the case for the final ferrite fraction.
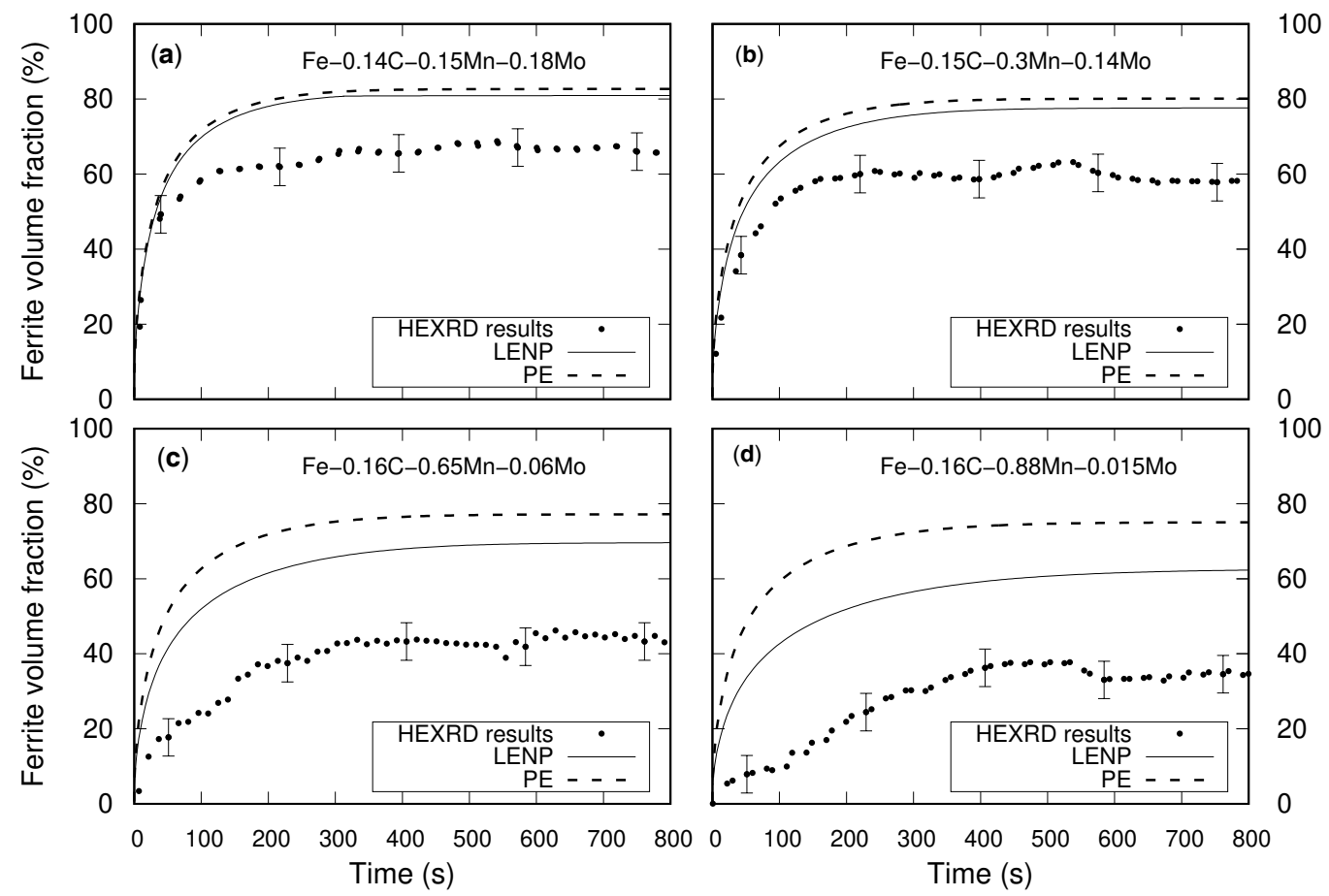

Figure 13. Experimental ferrite growth kinetics measured using HEXRD experiments for different compositions of the diffusion couple $\mathrm{Fe}-\mathrm{C}-\mathrm{Mn} / \mathrm{Fe}-\mathrm{C}-\mathrm{Mo}$ during the holding step at $760{ }^{\circ} \mathrm{C}$ for $20 \mathrm{~min}$ : (a) Fe-0.14C-0.15Mn-0.18Mo (\%wt.); (b) Fe-0.15C-0.3Mn-0.14Mo (\%wt.); (c) Fe-0.16C-0.65Mn-0.06Mo (\%wt.); and (d) Fe-0.16C-0.88Mn-0.015Mo (\%wt.). The calculated kinetics using LENP and PE models are shown for the different compositions.

\section{Discussion}

The use of HEXRD technique on compositionally graded materials allowed obtaining time- and space-resolved austenite-to-ferrite transformation kinetics. To illustrate the effect of composition on ferrite growth kinetics, experimental results were compared with calculations using LENP and PE models. 


\subsection{Effect of Mn on Ferrite Growth}

The comparison between the ferrite fractions reached at the stasis of transformation at $760{ }^{\circ} \mathrm{C}$, in a ternary alloy $\mathrm{Fe}-\mathrm{C}-\mathrm{Mn}$ with a gradient of Mn content $(0-1 \% \mathrm{wt})$ and the predicted ones using LENP and PE models showed that, for low Mn content (up to $0.3 \% \mathrm{wt}$.), the measured fractions are in agreement with the predicted values. At higher Mn content, the measured fraction becomes lower than both LENP and PE predictions but closer to LENP calculations. To illustrate this effect, Figure 14 shows the evolution of the degree of non-complete transformation with Mn content calculated from using the formula $\frac{f(P E / L E N P)-f(E X)}{f(P E / L E N P)}$, where $f(P E / L E N P)$ is the obtained ferrite fraction using PE or LENP conditions and $f(E X)$ is the measured ferrite fraction at the stasis stage, as introduced by Chen et al. [36]. The non-complete transformation degree increases with Mn content. Using LENP conditions, the degree of IC transformation reaches a plateau at $0.65 \%$ wt. of $\mathrm{Mn}$, while the PE corresponding IC transformation degree increases linearly with Mn content. This effect of non-complete transformation was already observed in $\mathrm{Fe}-\mathrm{C}-\mathrm{Mn}$ alloys by $\mathrm{Chen}$ et al. [36,37]. This phenomenon was explained by the segregation of $\mathrm{Mn}$ atoms at the moving interface causing a dissipation of the available driving force. The dissipation energy increases with Mn content and when it becomes higher than the available driving energy, the transformation stops or becomes too sluggish. During this "stasis stage", the interface is stationary or moving very slowly.

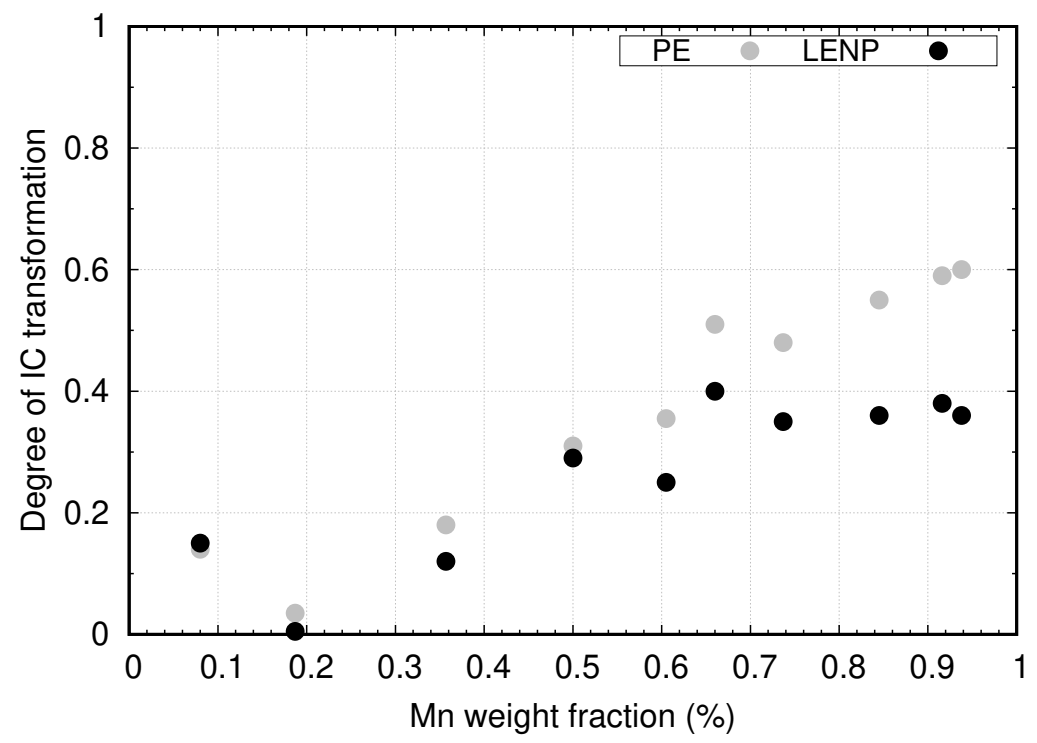

Figure 14. The degree of incomplete transformation as function of Mn content at $760{ }^{\circ} \mathrm{C}$.

\subsection{Effect of Mn and Mo on Ferrite Growth Kinetics}

In Figure 13, the measured ferrite growth kinetics for different compositions of Mo and Mn in quaternary $\mathrm{Fe}-\mathrm{C}-\mathrm{Mn}-\mathrm{Mo}$ is compared to the predicted kinetics using PE and LENP approaches. The results show that, with increasing Mn content and decreasing Mo content, the transformation becomes slower compared to PE and LENP calculations and the ferrite fraction at the stasis stage becomes lower. The incomplete transformation phenomenon is again observed in this system and it intensifies with increasing $\mathrm{Mn}$ content and decreasing Mo content. In quaternary $\mathrm{Fe}-\mathrm{C}-\mathrm{X}-\mathrm{Y}$ and higher order systems, the effect of substitutional elements on phase transformation kinetics becomes more complex due to the possible solute-solute interaction at the interface and its effect on the segregation behavior of substitutional elements [22]. In austenite-to-ferrite phase transformation, this effect is known as coupled solute drag effect [22,23]. In Fe-C-Mn-Mo system, the incomplete transformation was already observed in previous studies [38,39]. Xia et al. [38] showed that adding 0.3Mo to a $\mathrm{Fe}-0.1 \mathrm{C}-1.5 \mathrm{Mn}(\% \mathrm{wt})$ induced a transformation stasis at $550-600{ }^{\circ} \mathrm{C}$ but not at $500{ }^{\circ} \mathrm{C}$ where $\mathrm{Mo}$ showed no effect on the plateau of transformation. They also showed that adding Mo could affect the 
kinetics by retarding the transformation. In another study, the same authors [39] conducted a series of ferrite/bainite precipitation experiments on Fe-0.12C-1.49Mn-xMo (wt. \%) with different Mo contents at $550{ }^{\circ} \mathrm{C}$. The results show that adding Mo does not affect the kinetics but it clearly has an effect on the plateau volume fraction. In the present study, the first results indicate an effect of Mo (and Mn) on both kinetics and stasis volume fraction.

\section{Artifacts and Possible Solutions}

As shown in this study, the use of HEXRD coupled with compositionally graded materials can generate a large amount of data that can be used in studying ferrite growth kinetics in ternary $\mathrm{Fe}-\mathrm{C}-\mathrm{X}$ and quaternary $\mathrm{Fe}-\mathrm{C}-\mathrm{X}-\mathrm{Y}$ systems ( $\mathrm{X}$ and $\mathrm{Y}$ are substitutional elements). However, some experimental difficulties were encountered during the development of the methodology, making the interpretation of the obtained results more difficult, even impossible in certain cases.

- The first problem was the coarse grain size of the graded samples, which resulted in discontinuous 2D diffraction patterns and subsequent shouldered peaks, making the Rietveld adjustment more difficult and resulting in errors on the calculated phase fractions. One solution to overcome this problem is to use a newly developed furnace with a rotating sample holder. This configuration will lead to an increased number of analyzed grains and an average pattern over the rotation angle, which should in turn translate into more continuous Debye-Scherrer rings. This furnace was already used on a synchrotron beam line in other studies and showed good results $[40,41]$.

- The second problem encountered in developing the methodology was decarburization during phase transformation experiments. As mentioned above, a layer of ferrite was observed on samples surface at the end of HEXRD experiments. This artifact resulted in errors over the measured ferrite fraction. The furnace mentioned above also features superior atmosphere control and should solve this issue as well.

- The last and most important complication was related to the through-thickness gradient of composition generated during cold rolling, due to a deformation disparity between the surfaces and the center of samples, which prevented measuring the transformation at constant composition for a given $\mathrm{X}$-ray beam position. The through-thickness composition profile was measured by EPMA, and only datasets where there was no through-thickness gradient are presented here. A significant number of gradient samples had to be discarded based on this criterion. The many low-reduction passes are suspected to have amplified the through-thickness inhomogeneity of deformation normally expected from rolling. However, we are not able at this point to precisely determine the conditions on the alloy's rheology, sample geometry, and rolling schedule that would minimize this effect. One of the solutions would be to use higher reductions to promote a more homogeneous deformation. It is thought that this could be achieved with a minimal number of high-reduction hot rolling passes. Alternatively, the plastic deformation step could be skipped altogether and the long composition gradients generated using thermal treatments only. To this end, diffusion should be carried out in the delta ferrite range where the diffusion of substitutional elements is 100 times faster than in austenite. However, this is possible only in low carbon samples. Thus, millimeter scale composition gradients would be formed first and the required amount of carbon would be reintroduced by re-carburizing the samples. Prolonged high temperature treatments without deformation make grain size control particularly challenging with this method. In this case, cyclic austenitization and quench can be used to refine the microstructure [42].

These proposed solutions are being studied and results will be presented in an upcoming paper.

\section{Conclusions}

In the present study, we developed a complete methodology to study the effect of substitutional element contents on ferrite growth kinetics in ternary $\mathrm{Fe}-\mathrm{C}-\mathrm{X}$ and quaternary $\mathrm{Fe}-\mathrm{C}-\mathrm{X}-\mathrm{Y}$ systems (where $X$ and $Y$ are substitutional elements). Diffusion couples containing gradients of composition 
were made by hot compression to create solid-state joints between different samples, followed by high temperature diffusion and plastic deformation to generate and extend the composition gradients. High-energy $\mathrm{X}$-ray diffraction was used to gather ferrite growth kinetics at inter-critical temperatures within the substitutional gradients. The results obtained for a diffusion couple containing a gradient of $\mathrm{Mn}$ and another one containing opposite gradients of $\mathrm{Mn}$ and Mo are presented to illustrate the effect of $\mathrm{Mn}$ and $\mathrm{Mn} / \mathrm{Mo}$ contents on ferrite fraction formed at $760^{\circ} \mathrm{C}$ and $730^{\circ} \mathrm{C}$, respectively. For both systems, the obtained fractions deviated from the predicted ones using LENP and PE models. These results highlight the importance of high-throughput methods in studying the effect of composition on austenite to ferrite phase transformation. The large datasets generated using this method can be used to validate and optimize the existing models describing phase transformation kinetics in steels.

However, some experimental issues were encountered during this study making the quantitative interpretation of the obtained results more difficult. Some solutions are being studied to overcome these complexities.

Author Contributions: This work is part of I.-E.B.'s PhD thesis who performed most of the experimental work and wrote the paper. H.P.V.L. and A.D. are I.-E.B.'s PhD supervisors. They participated in the HEXRD experiments and edited the paper. F.B. is I.-E.B.'s industrial supervisor. He provided the materials and helped with the definition of the processing conditions. F.R. helped with the EPMA measurements of composition gradients. All authors have read and agreed to the published version of the manuscript

Funding: I.-E.B.'s PhD scholarship is funded by Grenoble Institute of Technology. Additional funding for the experimental work was provided by ArcelorMittal Research SA and by Univ. Grenoble Alpes through a strategic research initiative (IRS) grant.

Acknowledgments: ESRF support on ID11 beamline and with the use of ETMT device is gratefully acknowledged, particularly from T. Buslaps and J. Wright. G. Geandier is thanked for fruitful discussions and for help with the use of Fullprof software.

Conflicts of Interest: The authors declare no conflict of interest.

\section{References}

1. Bhadeshia, H.; Honeycombe, R. Steels: Microstructure and Properties; Elsevier: Amsterdam, The Netherlands, 2011; Google-Books-ID: 6MtuBqok43MC.

2. Bhadeshia, H.K.D.H. Diffusional formation of ferrite in iron and its alloys. Prog. Mater. Sci. 1985, 29, 321-386. [CrossRef]

3. Gouné, M.; Danoix, F.; Ågren, J.; Bréchet, Y.; Hutchinson, C.; Militzer, M.; Purdy, G.; van der Zwaag, S.; Zurob, H. Overview of the current issues in austenite to ferrite transformation and the role of migrating interfaces therein for low alloyed steels. Mater. Sci. Eng. R Rep. 2015, 92, 1-38. [CrossRef]

4. Enomoto, M. Comparison of alloy element partition behavior and growth kinetics of proeutectoid ferrite in Fe-C-X alloys with diffusion growth theory. ISIJ Int. 1988, 28, 826-835. [CrossRef]

5. Enomoto, M. Local conditions at moving $\alpha / \gamma$ Boundaries of proeutectoid ferrite transformation in iron alloys. Metall. Mater. Trans. A 2006, 37, 1703-1710. [CrossRef]

6. Gilmour, J.B.; Purdy, G.R.; Kirkaldy, J.S. Partition of manganese during the proeutectoid ferrite transformation in steel. MT 1972, 3, 3213-3222. [CrossRef]

7. Purdy, G. The dynamics of transformation interfaces in steels-II. Transformations in FE-C-MO alloys at intermediate temperatures. Acta Metall. 1978, 26, 487-498. [CrossRef]

8. Gamsjäger, E.; Svoboda, J.; Fischer, F. Austenite-to-ferrite phase transformation in low-alloyed steels. Comput. Mater. Sci. 2005, 32, 360-369. [CrossRef]

9. Oi, K.; Lux, C.; Purdy, G. A study of the influence of Mn and Ni on the kinetics of the proeutectoid ferrite reaction in steels. Acta Mater. 2000, 48, 2147-2155. [CrossRef]

10. Van der Ven, A.; Delaey, L. Models for precipitate growth during the $\gamma \rightarrow \alpha+\gamma$ transformation in Fe-C and Fe-C-M alloys. Prog. Mater. Sci. 1996, 40, 181-264. [CrossRef]

11. Hillert, M. Nature of local equilibrium at the interface in the growth of ferrite from alloyed austenite. Scr. Mater. 2002, 46, 447-453. [CrossRef]

12. Coates, D.E. Diffusion-controlled precipitate growth in ternary systems I. Metall. Mater. Trans. B 1972, 3, 1203-1212. [CrossRef] 
13. Hutchinson, C.R.; Fuchsmann, A.; Brechet, Y. The diffusional formation of ferrite from austenite in Fe-C-Ni alloys. Metall. Mater. Trans. A 2004, 35, 1211-1221. [CrossRef]

14. Cahn, J.W. The impurity-drag effect in grain boundary motion. Acta Metall. 1962, 10, 789-798. [CrossRef]

15. Hillert, M.; Sundman, B. A treatment of the solute drag on moving grain boundaries and phase interfaces in binary alloys. Acta Metall. 1976, 24, 731-743. [CrossRef]

16. Danoix, F.; Sauvage, X.; Huin, D.; Germain, L.; Gouné, M. A direct evidence of solute interactions with a moving ferrite/austenite interface in a model Fe-C-Mn alloy. Scr. Mater. 2016, 121, 61-65. [CrossRef]

17. Van Landeghem, H.P.; Langelier, B.; Gault, B.; Panahi, D.; Korinek, A.; Purdy, G.R.; Zurob, H.S. Investigation of solute/interphase interaction during ferrite growth. Acta Mater. 2017, 124, 536-543. [CrossRef]

18. Guo, H.; Purdy, G.R.; Enomoto, M.; Aaronson, H.I. Kinetic transitions and substititional solute (Mn) fields associated with later stages of ferrite growth in Fe-C-Mn-Si. Metall. Mater. Trans. A 2006, 37, 1721-1729. [CrossRef]

19. Purdy, G.R.; Brechet, Y.J.M. A solute drag treatment of the effects of alloying elements on the rate of the proeutectoid ferrite transformation in steels. Acta Metall. Mater. 1995, 43, 3763-3774. [CrossRef]

20. Odqvist, J.; Sundman, B.; Ågren, J. A general method for calculating deviation from local equilibrium at phase interfaces. Acta Mater. 2003, 51, 1035-1043. [CrossRef]

21. Zurob, H.S.; Panahi, D.; Hutchinson, C.R.; Brechet, Y.; Purdy, G.R. Self-Consistent Model for Planar Ferrite Growth in Fe-C-X Alloys. Metall. Mater. Trans. A 2013, 44, 3456-3471. [CrossRef]

22. Qiu, C.; Zurob, H.; Hutchinson, C. The coupled solute drag effect during ferrite growth in Fe-C-Mn-Si alloys using controlled decarburization. Acta Mater. 2015, 100, 333-343. [CrossRef]

23. Sun, W.; Zurob, H.; Hutchinson, C. Coupled solute drag and transformation stasis during ferrite formation in Fe-C-Mn-Mo. Acta Mater. 2017, 139, 62-74. [CrossRef]

24. Hutchinson, C. A novel experimental approach to identifying kinetic transitions in solid state phase transformations. Scr. Mater. 2004, 50, 285-290. [CrossRef]

25. Deschamps, A.; Tancret, F.; Benrabah, I.E.; De Geuser, F.; Van Landeghem, H.P. Combinatorial approaches for the design of metallic alloys. C. R. Phys. 2018, 19, 737-754. [CrossRef]

26. Raabe, D.; Springer, H.; Gutierrez-Urrutia, I.; Roters, F.; Bausch, M.; Seol, J.B.; Koyama, M.; Choi, P.P.; Tsuzaki, K. Alloy Design, Combinatorial Synthesis, and Microstructure-Property Relations for Low-Density Fe-Mn-Al-C Austenitic Steels. JOM 2014, 66, 1845-1856. [CrossRef]

27. Zhao, J.C.; Zheng, X.; Cahill, D.G. Thermal conductivity mapping of the Ni-Al system and the beta-NiAl phase in the Ni-Al-Cr system. Scr. Mater. 2012, 66, 935-938. [CrossRef]

28. Zhao, J.C. A combinatorial approach for efficient mapping of phase diagrams and properties. J. Mater. Res. 2001, 16, 1565-1578. [CrossRef]

29. Sinclair, C.; Hutchinson, C.; Bréchet, Y. The Effect of $\mathrm{Nb}$ on the Recrystallization and Grain Growth of Ultra-High-Purity $\alpha$-Fe: A Combinatorial Approach. Metall. Mater. Trans. A 2007, 38, 821-830. [CrossRef]

30. De Geuser, F.; Styles, M.; Hutchinson, C.; Deschamps, A. High-throughput in-situ characterization and modeling of precipitation kinetics in compositionally graded alloys. Acta Mater. 2015, 101, 1-9. [CrossRef]

31. Gumbmann, E.; De Geuser, F.; Deschamps, A.; Lefebvre, W.; Robaut, F.; Sigli, C. A combinatorial approach for studying the effect of $\mathrm{Mg}$ concentration on precipitation in an Al-Cu-Li alloy. Scr. Mater. 2016, 110, 44-47. [CrossRef]

32. Geandier, G.; Aeby-Gautier, E.; Settefrati, A.; Dehmas, M.; Appolaire, B. Study of diffusive transformations by high energy X-ray diffraction. C. R. Phys. 2012, 13, 257-267. [CrossRef]

33. Esin, V.; Denand, B.; Le Bihan, Q.; Dehmas, M.; Teixeira, J.; Geandier, G.; Denis, S.; Sourmail, T.; Aeby-Gautier, E. In situ synchrotron X-ray diffraction and dilatometric study of austenite formation in a multi-component steel: Influence of initial microstructure and heating rate. Acta Mater. 2014, 80, 118-131. [CrossRef]

34. Thermo-Calc Software. Available online: www.thermocalc.com (accessed on 15 July 2019).

35. Robaut, F.; Crisci, A.; Durand-Charre, M.; Jouanne, D. Practical Aspects of Carbon Content Determination in Carburized Steels by EPMA. Microsc. Microanal. 2006, 12, 331-334. [CrossRef] [PubMed]

36. Chen, H.; Kuziak, R.; van der Zwaag, S. Experimental Evidence of the Effect of Alloying Additions on the Stagnant Stage Length During Cyclic Partial Phase Transformations. Metall. Mater. Trans. A 2013, 44, 5617-5621. [CrossRef] 
37. Chen, H.; van der Zwaag, S. A general mixed-mode model for the austenite-to-ferrite transformation kinetics in Fe-C-M alloys. Acta Mater. 2014, 72, 1-12. [CrossRef]

38. Xia, Y.; Miyamoto, G.; Yang, Z.; Zhang, C.; Furuhara, T. Direct measurement of carbon enrichment in the incomplete bainite transformation in Mo added low carbon steels. Acta Mater. 2015, 91, 10-18. [CrossRef]

39. Xia, Y.; Miyamoto, G.; Yang, Z.G.; Zhang, C.; Furuhara, T. Effects of Mo on Carbon Enrichment During Proeutectoid Ferrite Transformation in Hypoeutectoid Fe-C-Mn Alloys. Metall. Mater. Trans. A 2015, 46, 2347-2351. [CrossRef]

40. Bénéteau, A.; Weisbecker, P.; Geandier, G.; Aeby-Gautier, E.; Appolaire, B. Austenitization and precipitate dissolution in high nitrogen steels: An in situ high temperature X-ray synchrotron diffraction analysis using the Rietveld method. Mater. Sci. Eng. A 2005, 393, 63-70. [CrossRef]

41. Bruneseaux, F.; Aeby-Gautier, E.; Geandier, G.; Da Costa Teixeira, J.; Appolaire, B.; Weisbecker, P.; Mauro, A. In situ characterizations of phase transformations kinetics in the Ti17 titanium alloy by electrical resistivity and high temperature synchrotron X-ray diffraction. Mater. Sci. Eng. A 2008, 476, 60-68. [CrossRef]

42. Grange, R.A. The rapid heat treatment of steel. Metall. Trans. 1971, 2, 65-78. [CrossRef]

(C) 2019 by the authors. Licensee MDPI, Basel, Switzerland. This article is an open access article distributed under the terms and conditions of the Creative Commons Attribution (CC BY) license (http:/ / creativecommons.org/licenses/by/4.0/). 